DOI: 10.3724/SP.J.1006.2008.00809

\title{
不同耐镉基因型水稻农艺和生理性状的比较研究
}

\author{
黄冬芬奚岭林杨立年王志琴杨建昌"
}

(扬州大学江苏省作物遗传生理重点实验室，江苏扬州 225009)

摘 要：于 2004 和 2005 年在扬州大学试验农场进行了不同耐镉基因型水稻农艺和生理性状的比较研究。2 个耐镉(Cd) 基因型汕优 63(杂交籼稻)和扬粳 9538(粳稻)及 2 个 Cd 敏感基因型扬稻 6 号(籼稻)和武运粳 7 号(粳稻)种植于盆钵。 于移栽前盆钵土中加人 $\mathrm{Cd}$, 浓度为 $150 \mathrm{mg} \mathrm{kg}{ }^{-1}(\mathrm{Cd}$ 处理), 以未加 $\mathrm{Cd}$ 为对照( $\mathrm{CK})$ 。 $\mathrm{Cd}$ 处理后, 耐 $\mathrm{Cd}$ 基因型籽粒产 量较 CK 降低 $6.2 \%$ 8.9\%, Cd 敏感基因型产量较对照降低 38.3\% 47.1\%。每盆穗数和每穗颖花数显著减少是减产的 主要原因, 结实率和千粒重在 $\mathrm{Cd}$ 处理和 $\mathrm{CK}$ 间无显著差异。 $\mathrm{Cd}$ 处理显著抑制 $\mathrm{Cd}$ 敏感基因型的分雀发生, 导致整个 生育期干物质积累的显著下降, 但对物质运转率和收获指数无显著影响。在 $\mathrm{Cd}$ 胁迫下, 分藮至拔节期 $\mathrm{Cd}$ 敏感基因 型的根系活力、叶片光合速率、超氧化物歧化酶和过氧化氢酶活性明显低于耐 $\mathrm{Cd}$ 基因型, 叶片超氧自由基和过氧化 氢含量、乙烯释放速率及根系伤流液中 1-氨基环丙烷-1-羧酸浓度则显著高于耐 $\mathrm{Cd}$ 基因型。抽穗以后 $\mathrm{Cd}$ 对上述生理 指标以及整个生育时期叶片脱落酸含量无显著影响。说明 $\mathrm{Cd}$ 对水稻生长发育的影响主要在生育前期(分偗至拔节期), 此期分蕃发生多、根系活力和叶片抗氧化保护系统能力强及乙烯合成少是耐 Cd 基因型水稻的主要农艺和生理特征。

关键词：水稻；耐镉基因型；活性氧系统；根系活力；乙烯

\section{Comparisons in Agronomic and Physiological Traits of Rice Genotypes Differing in Cadmium-Tolerance}

\author{
HUANG Dong-Fen, XI Ling-Lin, YANG Li-Nian, WANG Zhi-Qin, and YANG Jian-Chang* \\ (Key Laboratory of Crop Genetics and Physiology of Jiangsu Province, Yangzhou University, Yangzhou 225009, Jiangsu, China)
}

\begin{abstract}
Cadmium (Cd) is one of major contaminants in agricultural soil, threatening agricultural production and human health. To understand agronomic and physiological characteristics of rice genotypes differing in Cd-tolerance would have great significance in selecting or breeding a Cd-tolerant cultivar. In this study, two Cd-tolerant rice genotypes of Shanyou 63 (indica hybrid) and Yangjing 9538 (japonica) and two Cd-susceptible genotypes of Yangdao 6 (indica) and Wuyunjing 7 (japonica) were pot-grown at a farm of Yangzhou University, Yangzhou, Jiangsu Province in 2004 and 2005. $150 \mathrm{mg} \mathrm{kg}^{-1} \mathrm{Cd}$ was added into pot soil before seedling transplanting (Cd treatment), and no $\mathrm{Cd}$ addition was taken as control (CK). Under the $\mathrm{Cd}$ treatment, the grain yield was reduced by $6.2-8.9 \%$ for the Cd-tolerant genotypes and by $38.3-47.1 \%$ for the Cd-susceptible ones when compared with their respective CKs. The reduction in grain yield was mainly attributed to the reductions of panicles per pot and spikelets per panicle. The differences in seed-setting rate and 1000 -grain weight were not significant between the Cd treatment and CK. The $\mathrm{Cd}$ treatment markedly inhibited the tillering of the Cd-susceptible genotypes, resulting in the reduction in dry matter accumulation during the whole growth period. Cd little affected the translocation of non-structural carbohydrate from culms and sheaths and harvest index. For Cd-susceptible genotypes, the $\mathrm{Cd}$ treatment significantly reduced root oxidation activity and photosynthetic rate, activities of superoxide dismutase and catalase of leaves, and obviously increased contents of superoxidate radical and hydrogen peroxide and ethylene evolution rate of leaves, and the concentration of 1-aminocylopropane-1-carboxylic acid in root bleedings from the tillering to jointing stages, while the $\mathrm{Cd}$ treatment much less affected the above physiological traits for the Cd-tolerant genotypes. The differences in the above traits at heading and afterwards and abscisic acid content in leaves during the whole growth period were not significant between the $\mathrm{Cd}$ treatment and $\mathrm{CK}$. The results indicate that the effects of Cd on rice
\end{abstract}

基金项目: 国家自然科学基金项目(30671225,30771274); 江苏省自然科学基金项目(BK2006069)

作者简介: 黄冬芬 (1975-), 女, 海南陵水县人, 博士研究生, 从事作物生理学的研究。

*通讯作者(Corresponding author): 杨建昌。Tel: 0514-87979317, E-mail: jcyang@yzu.edu.cn

Received(收稿日期): 2007-07-24; Accepted(接受日期): 2007-11-05. 
growth and development are mainly during the early growth period (from tillering to jointing), and more tillers, stronger root activity and antioxidative defense system, and less ethylene synthesis in the plants during this period would be considered as agronomic and physiological traits of Cd-tolerant genotypes of rice.

Keywords: Rice; Cadmium-tolerant genotype; Reactive oxygen species; Root activity; Ethylene

镉 $(\mathrm{Cd})$ 是稻田最主要的重金属污染元素 ${ }^{[1]}$ 。在 $\mathrm{Cd}$ 污染严重的稻区，由于 $\mathrm{Cd}$ 的毒害作用可造成水 稻严重减产 ${ }^{[2-3]}$ 。随着我国工业特别是乡镇和个体小 型工业的发展, $\mathrm{Cd}$ 等重金属污染越来越严重。据不 完全统计, 我国重金属 $\mathrm{Cd}$ 污染农田面积已超过 28 万 $\mathrm{hm}^{2}$ ，每年生产 $\mathrm{Cd}$ 含量超标的农产品 14.6 亿 $\mathrm{kg}$, 对农业生产和人们的身体健康构成严重的威胁 ${ }^{[4-5]}$ 。 多年来, 国内外对 $\mathrm{Cd}$ 在作物中的吸收、运输和分配 以及对作物的毒害作用进行了较多的研究 ${ }^{[6-11]}$ 。近年 来, 我们在研究中发现, $\mathrm{Cd}$ 对水稻产量的影响在品 种间存在很大差异 ${ }^{[12]}$ 。对土壤进行加 $\mathrm{Cd}$ 处理后, 一 些水稻品种严重减产，另一些品种减产则不明显。 但对于耐 $\mathrm{Cd}$ 性不同品种的农艺和生理特征尚缺乏 深人研究。本试验比较了耐 $\mathrm{Cd}$ 和 $\mathrm{Cd}$ 敏感两类基因 型水稻产量形成和生理生化的差异, 以期为耐 $\mathrm{Cd}$ 性 品种的选用和选育提供理论依据。

\section{1 材料与方法}

\section{1 材料与栽培概况}

试验于 2004 和 2005 年在扬州大学农学院盆栽 场进行。供试材料为扬稻 6 号(籼稻)、汕优 63(杂交 籼稻)、武运粳 7 号(粳稻) 和扬粳 9538(粳稻)。这 4 个材料生育期为 150 155 d; 土壤 $\mathrm{Cd}$ 污染下生长发 育和产量形成存在明显基因型差异 ${ }^{[12]}$ 。5 月 10-11 日播种, 大田育苗, 6 月 10-11 日移栽至盆钵。盆内 径 $25 \mathrm{~cm}$, 高 $30 \mathrm{~cm}$, 每盆装过篮无污染沙壤土 $16 \mathrm{~kg}$ $\left(\mathrm{Cd}\right.$ 浓度 $\left.<0.3 \mathrm{mg} \mathrm{kg}^{-1}\right)$ 。每盆栽 3 穴, 汕优 63 每穴 1 苗, 其余品种每穴 2 苗。移栽前 $3 \mathrm{~d}$ 每盆施尿素 $1 \mathrm{~g}$ 和 $\mathrm{KH}_{2} \mathrm{PO}_{4} 0.5 \mathrm{~g}$, 移栽后 $7 \mathrm{~d}$ 每盆施尿素 $0.5 \mathrm{~g}$, 于穗 分化期每盆施尿素 $1 \mathrm{~g}$ 。移栽后全生育期盆钵内保持 $1 \sim 2 \mathrm{~cm}$ 水层。

\subsection{Cd 处理}

于秧苗移栽前 1 个月, 在盆钵土壤中加人 $\mathrm{Cd}$, 使土壤 $\mathrm{Cd}$ 浓度为 $150 \mathrm{mg} \mathrm{kg}$ (干基, 以 $\mathrm{CdCl}_{2} \cdot 2.5 \mathrm{H}_{2} \mathrm{O}$ 的形态与土混合)。笔者在预备试验中 观察到, 当土壤 $\mathrm{Cd}$ 浓度 $\leqslant 100 \mathrm{mg} \mathrm{kg}^{-1}, \mathrm{Cd}$ 对水稻农 艺与生理性状的影响在品种间差异很小, 为筛选耐 $\mathrm{Cd}$ 性品种, 提高了 $\mathrm{Cd}$ 浓度。盆内保持水层, $\mathrm{pH}$ 保
持在 6.0 , 使土壤与 $\mathrm{Cd}$ 进行平衡。以无 $\mathrm{Cd}$ 污染土壤 (不加 $\mathrm{Cd}$ ) 为对照 $(\mathrm{CK})$ 。用二亚乙基三胺五乙酸 (DTPA)提取测定，土壤的 DTPA-Cd 浓度未加 $\mathrm{Cd}$ 前 为 $0.032 \mathrm{mg} \mathrm{kg}^{-1}$, 加 $\mathrm{Cd}$ 后为 $82.6 \mathrm{mg} \mathrm{kg}^{-1}$ 。每处理 重复 40 盆, 其中 30 盆用于取样分析, 10 盆用于考种 计产。自平衡期至抽穗, 用塑料大棚挡雨, 以防 $\mathrm{Cd}$ 被雨水冲失。

\section{3 取样与测定}

自移栽至乳熟期, 各处理固定 10 盆, 每 $7 \mathrm{~d}$ 观 察一次每盆的茎榄数。于分睬中期(移栽后 $20 \mathrm{~d}$ )、拔 节期和抽穗期, 取样测定主茎或一次分菒最上展开 叶的超氧自由基( )、过氧化氢 $\left(\mathrm{H}_{2} \mathrm{O}_{2}\right)$ 和脱落酸 (ABA)含量、乙烯释放速率、超氧化物歧化酶 $(\mathrm{SOD})$ 和过氧化氢酶(CAT)活性以及根系伤流液中的 1-氨 基环丙烷 1-羧酸(ACC)浓度。参照 Srivalli 等 ${ }^{[13]}$ 方法 测定叶片 $\mathrm{O}_{2}^{-}$和 $\mathrm{H}_{2} \mathrm{O}_{2}$ 含量及 SOD 和 CAT 活性, 采用 何钟佩和 Bollmark 等 ${ }^{[14-15]}$ 介绍的酶联免疫法测定叶 片 $\mathrm{ABA}$ 含量, 叶片乙烯释放速率和根系伤流液的收 集与 ACC 浓度的测定方法见文献[16]和[17]。各处 理每次重复测定 5 叶(次)。

分别于分藥初期(移栽后 $10 \mathrm{~d}$ )、分榄中期、拔节 期、抽穗期、乳熟期和蜡熟期，用 LI-6400 便携式光 合仪(美国 LI-COR 公司生产)测定主茎或一次分蓝 最上展开叶光合速率, 各处理重复测定 6 叶; 各处 理取 6 穴测定地上部干物质重和根系活性(氧化力)。 参照杨建昌等的方法 ${ }^{[18]}$ 取根和测定根系活力。

分别于抽穗期和成熟期取各处理植株样本 3 盆, 先用水冲洗根系泥土, 然后用去离子水清洗整个植 株, 用吸水纸吸干表面水分。将稻株根、茎鞘、叶、 穗(成熟期籽粒)分开, 于 $70^{\circ} \mathrm{C}$ 烘箱烘干至恒重, 然 后磨碎, 过 100 目篮, 称重, 用 $\mathrm{HNO}_{3}$ 加 $\mathrm{HClO}_{4}$ (4: 1)消化后, 用原子吸收光谱仪 (Solar S4 + Graphite Furnace System 97, Thermo Elemental, USA)测定各 部位 $\mathrm{Cd}$ 含量, 各样品重复测定 4 次。

于成熟期各处理取 10 盆计产, 取其中 3 盆考 种。将抽穗期和成熟期的取样植株, 分成叶、茎+ 鞘、穗 3 部分并烘干后, 按 Yoshida 等方法 ${ }^{[19]}$ 测定茎 与鞘中的非结构性碳水化合物(NSC)含量。 
茎鞘物质运转率 $=($ 抽穗期茎鞘中 $\mathrm{NSC}-$ 成熟 期茎鞘中 NSC)/抽穗期茎鞘中 NSC $\times 100 \%$

收获指数 $=$ 籽粒干重/成熟期地上部分总干重

\section{4 数据处理}

用 SAS (version 6.12; SAS Institute, Cary, NC, USA)进行统计分析, 用 $P=0.05$ 最小显著极差法 $\left(L S D_{0.05}\right)$ 进行平均数显著性检验。因两年的试验结果 趋势基本一致, 故本文除产量数据外, 其他数据用 两年的平均数表示。

\section{2 结果与分析}

\section{1 产量及其构成因素}

由表 1 可知, $\mathrm{Cd}$ 处理对产量的影响在基因型间 存在很大差异。 $\mathrm{Cd}$ 处理后, 汕优 63 和扬粳 9538 产
量仅较 CK 下降 6.2\% 8.9\%，与对照差异不显著; 而 扬稻 6 号和武运粳 7 号产量较 $\mathrm{CK}$ 降低了 $38.3 \%$ 47.1\%，与对照差异显著(表 1)。为便于分析 比较, 将在 $\mathrm{Cd}$ 胁迫下没有显著减产 (减产率 $<10 \%)$ 的汕优 63 和扬粳 9538 称为耐 $\mathrm{Cd}$ 基因型, 在 $\mathrm{Cd}$ 胁 迫下显著减产(减产率>30\%)的扬稻 6 号和武运粳 7 号称之为 $\mathrm{Cd}$ 敏感基因型。从产量构成因素分析, $\mathrm{Cd}$ 敏感基因型的每盆穗数和每穗粒数(颖花数)在 $\mathrm{Cd}$ 处 理下均显著下降。虽 $\mathrm{Cd}$ 处理后两耐 $\mathrm{Cd}$ 基因型的每 盆穗数和每穗颖花数较 $\mathrm{CK}$ 也有所减少, 但与 $\mathrm{CK}$ 无 显著差异。 $\mathrm{Cd}$ 处理对各基因型的结实率和千粒重均 无显著影响。说明 $\mathrm{Cd}$ 对产量形成的影响主要在生育 前中期。两年的结果趋势一致, 方差分析表明, 产量 和各产量构成因素在年度间均无显著差异 $(F<1)$ 。

表 1 镉处理对不同基因型水稻产量与产量构成因素的影响

Table 1 Effect of cadmium (Cd) treatment on the grain yield and its components of rice genotypes

\begin{tabular}{|c|c|c|c|c|c|c|c|}
\hline \multirow{2}{*}{$\begin{array}{c}\text { 基因型 } \\
\text { Genotype }\end{array}$} & \multirow{2}{*}{$\begin{array}{c}\text { 处理 } \\
\text { Treatment }\end{array}$} & \multirow{2}{*}{$\begin{array}{c}\text { 每盆穗数 } \\
\text { Panicles per pot }\end{array}$} & \multirow{2}{*}{$\begin{array}{c}\text { 每穗粒数 } \\
\text { Spikelets per panicle }\end{array}$} & \multirow{2}{*}{$\begin{array}{c}\text { 结实率 } \\
\text { Seed-setting rate }(\%)\end{array}$} & \multirow{2}{*}{$\begin{array}{c}\text { 千粒重 } \\
\text { 1000-grain weight (g) }\end{array}$} & \multicolumn{2}{|c|}{ 产量 Grain yield } \\
\hline & & & & & & $\mathrm{g} \mathrm{pot}^{-1}$ & $\%$ \\
\hline \multicolumn{8}{|l|}{2004} \\
\hline 扬稻 6 号 & CK & $21 \mathrm{a}$ & $147 \mathrm{a}$ & 88.9 a & $27.2 \mathrm{a}$ & $74.6 \mathrm{a}$ & 100.0 \\
\hline Yangdao 6 & $\mathrm{Cd}$ & $14 \mathrm{~b}$ & $132 \mathrm{~b}$ & $90.3 \mathrm{a}$ & $27.6 \mathrm{a}$ & $46.0 \mathrm{~b}$ & 61.7 \\
\hline 汕优 63 & CK & $22 \mathrm{a}$ & $151 \mathrm{a}$ & $85.4 \mathrm{a}$ & $26.8 \mathrm{a}$ & $76.0 \mathrm{a}$ & 100.0 \\
\hline Shanyou 63 & $\mathrm{Cd}$ & $21 \mathrm{a}$ & $148 \mathrm{a}$ & $84.6 \mathrm{a}$ & $27.1 \mathrm{a}$ & $71.3 \mathrm{a}$ & 93.8 \\
\hline 武运粳 7 号 & $\mathrm{CK}$ & $26 \mathrm{a}$ & $116 \mathrm{a}$ & $87.6 \mathrm{a}$ & $29.3 \mathrm{a}$ & $77.4 \mathrm{a}$ & 100.0 \\
\hline Wuyunjing 7 & $\mathrm{Cd}$ & $17 \mathrm{~b}$ & $95 \mathrm{~b}$ & $88.1 \mathrm{a}$ & $29.7 \mathrm{a}$ & $42.3 \mathrm{~b}$ & 54.6 \\
\hline 扬粳 9538 & CK & $24 \mathrm{a}$ & $126 \mathrm{a}$ & $86.7 \mathrm{a}$ & $25.6 \mathrm{a}$ & $67.1 \mathrm{a}$ & 100.0 \\
\hline Yangjing 9538 & $\mathrm{Cd}$ & $23 \mathrm{a}$ & $123 \mathrm{a}$ & $85.5 \mathrm{a}$ & $25.4 \mathrm{a}$ & $61.4 \mathrm{a}$ & 91.5 \\
\hline \multicolumn{8}{|l|}{2005} \\
\hline 扬稻 6 号 & CK & $23 \mathrm{a}$ & $151 \mathrm{a}$ & $85.4 \mathrm{a}$ & $26.8 \mathrm{a}$ & $79.5 \mathrm{a}$ & 100.0 \\
\hline Yangdao 6 & $\mathrm{Cd}$ & $15 \mathrm{~b}$ & $136 \mathrm{~b}$ & $84.6 \mathrm{a}$ & $26.7 \mathrm{a}$ & $46.1 \mathrm{~b}$ & 58.0 \\
\hline 汕优 63 & CK & $24 \mathrm{a}$ & $162 \mathrm{a}$ & $81.5 \mathrm{a}$ & $26.2 \mathrm{a}$ & $83.0 \mathrm{a}$ & 100.0 \\
\hline Shanyou 63 & $\mathrm{Cd}$ & $22 \mathrm{a}$ & $163 \mathrm{a}$ & $81.7 \mathrm{a}$ & $26.3 \mathrm{a}$ & $77.1 \mathrm{a}$ & 92.9 \\
\hline 武运粳 7 号 & CK & $25 \mathrm{a}$ & $121 \mathrm{a}$ & $85.4 \mathrm{a}$ & $27.5 \mathrm{a}$ & $71.0 \mathrm{a}$ & 100.0 \\
\hline Wuyunjing 7 & $\mathrm{Cd}$ & $15 \mathrm{~b}$ & $108 \mathrm{~b}$ & $83.7 \mathrm{a}$ & $27.7 \mathrm{a}$ & $37.6 \mathrm{~b}$ & 52.9 \\
\hline 扬粳 9538 & $\mathrm{CK}$ & $23 \mathrm{a}$ & $130 \mathrm{a}$ & $82.6 \mathrm{a}$ & $24.9 \mathrm{a}$ & $61.5 \mathrm{a}$ & 100.0 \\
\hline Yangjing 9538 & $\mathrm{Cd}$ & $21 \mathrm{a}$ & $128 \mathrm{a}$ & $83.0 \mathrm{a}$ & $25.1 \mathrm{a}$ & $56.0 \mathrm{a}$ & 91.1 \\
\hline
\end{tabular}

同一基因型(品种)内标以不同字母者表示 $\mathrm{Cd}$ 处理与对照(CK)间在 $P=0.05$ 水平上差异显著。

Values within a column for a genotype followed by a different letter are significantly different between $\mathrm{Cd}$ treatment and $\mathrm{CK}$ at $P=0.05$.

\section{2 分菜动态与物质生产}

$\mathrm{Cd}$ 处理明显抑制了 $\mathrm{Cd}$ 敏感基因型的分檴发生 (图 1)。与 $\mathrm{CK}$ 相比，在 $\mathrm{Cd}$ 处理下这些基因型表现 为分藥发生慢、分藥数量少。虽分葟成穗率较高，但 因分藥数少而最终成穗数低。 $\mathrm{Cd}$ 对两耐 $\mathrm{Cd}$ 基因型 的分策发生影响很小。虽在 $\mathrm{Cd}$ 处理下的最高分藥数
少于 $\mathrm{CK}$ ，但最终成穗数与 $\mathrm{CK}$ 无显著差异(图 1)。

与茎繤的发生相类似, $\mathrm{Cd}$ 处理明显地降低了干 物质的累积(表 2)。 $\mathrm{Cd}$ 对干物质重的影响, $\mathrm{Cd}$ 敏感 基因型明显大于耐 $\mathrm{Cd}$ 基因型。例如在抽穗期, $\mathrm{Cd}$ 处 理后 $\mathrm{Cd}$ 敏感基因型扬稻 6 号和武运粳 7 号的干物质 重较 CK 分别下降了 $40.2 \%$ 和 $45.1 \%$; 耐 $\mathrm{Cd}$ 基因型 
汕优 63 和扬粳 9538 的干物质重, $\mathrm{Cd}$ 处理后分别较 $\mathrm{CK}$ 降低了 $3.2 \%$ 和 $9.2 \%$ 。 $\mathrm{Cd}$ 处理对茎鞘物质运转率 和收获指数无显著影响(表 2)。说明 $\mathrm{Cd}$ 主要通过抑 制分繤的发生, 导致物质生产能力的下降, 对物质 运转的影响则很小。

为了比较分析两类基因型对 $\mathrm{Cd}$ 吸收能力的差 异, 于抽穗期和成熟期测定了各处理水稻各器官 $\mathrm{Cd}$ 浓度及其累积量, 结果列于表 3(土壤中未加 $\mathrm{Cd}$ 的对照, 因植株各器官检测不到 $\mathrm{Cd}$, 故数据未列
出)。由表 3 可见, 根、茎鞘 + 叶、穗/籽粒中 $\mathrm{Cd}$ 浓 度在各供试基因型间均无显著差异, 但各器官的 $\mathrm{Cd}$ 累积量，耐 $\mathrm{Cd}$ 基因型显著高于 $\mathrm{Cd}$ 敏感基因型。 说明单位根重对 $\mathrm{Cd}$ 的吸收量及单位干重 $\mathrm{Cd}$ 的分配 量在耐 $\mathrm{Cd}$ 基因型与 $\mathrm{Cd}$ 敏感基因型间无显著差别, $\mathrm{Cd}$ 的累积量主要由干物质重量决定。耐 $\mathrm{Cd}$ 基因型 各器官的 $\mathrm{Cd}$ 累积量高, 不是因为单位干重的 $\mathrm{Cd}$ 吸 收能力强, 而是由于其物质生产能力强、干物质累 积量大。
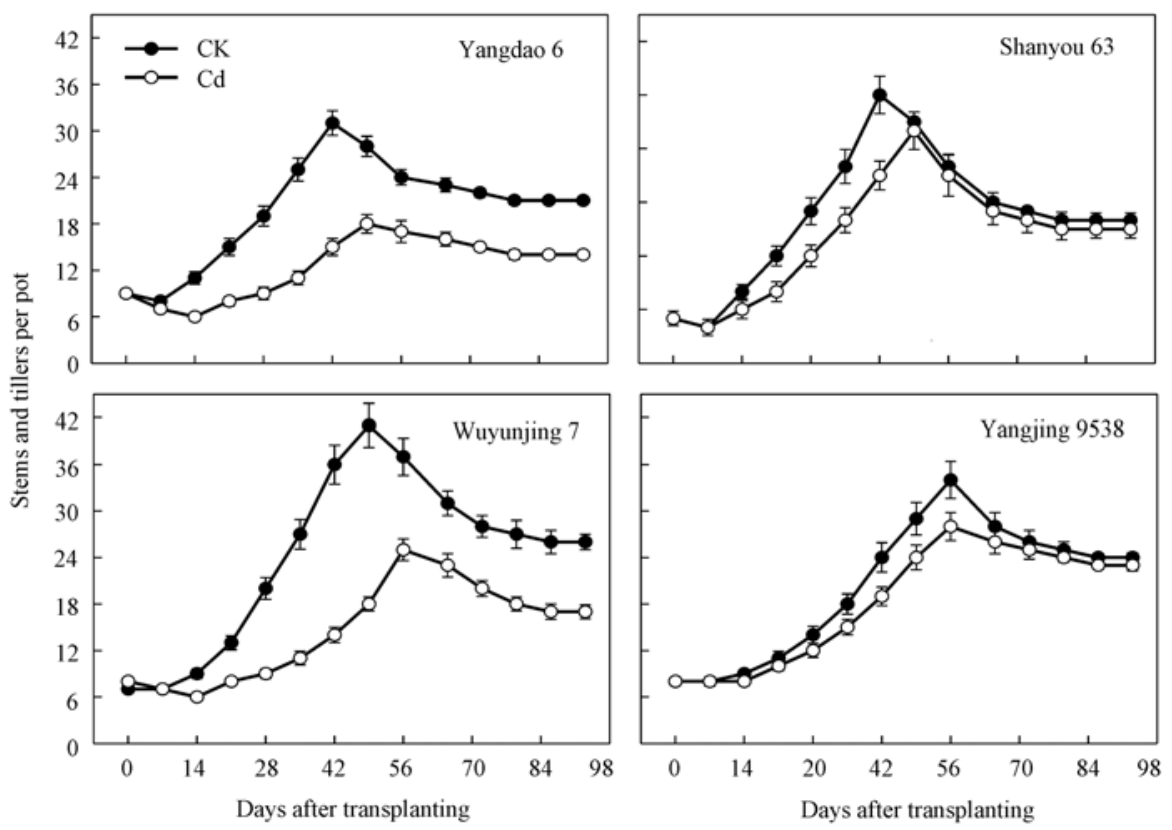

图 $1 \mathrm{Cd}$ 处理对水稻茎藮消长的影响

Fig. 1 Effect of Cd treatment on the increase or decrease of stems and tillers of rice 数据为 2 年的平均值。Data presented are averages between the two years.

表 2 镉处理对水稻干物质重和物质运转的影响

Table 2 Effect of cadmium (Cd) treatment on the dry matter weight and mater translocation of rice

\begin{tabular}{|c|c|c|c|c|c|c|c|}
\hline $\begin{array}{c}\text { 基因型 } \\
\text { Genotype }\end{array}$ & $\begin{array}{c}\text { 处理 } \\
\text { Treatment }\end{array}$ & $\begin{array}{c}\text { 分葟中期 } \\
\text { Mid-tillering } \\
\left(\mathrm{g} \mathrm{pot}^{-1}\right)\end{array}$ & $\begin{array}{l}\text { 拔节期 } \\
\text { Jointing } \\
\left(\mathrm{g} \mathrm{pot}^{-1}\right)\end{array}$ & $\begin{array}{l}\text { 抽穗期 } \\
\text { Heading } \\
\left(\mathrm{g} \mathrm{pot}^{-1}\right)\end{array}$ & $\begin{array}{l}\text { 成熟期 } \\
\text { Maturity } \\
\left(\mathrm{g} \mathrm{pot}^{-1}\right)\end{array}$ & $\begin{array}{c}\text { 物质运转率 } \\
\text { Matter translocation } \\
(\%)\end{array}$ & $\begin{array}{c}\text { 收获指数 } \\
\text { Harvest index }\end{array}$ \\
\hline 扬稻 6 号 & CK & $6.23 \mathrm{a}$ & $31.8 \mathrm{a}$ & $98.5 \mathrm{a}$ & $157.0 \mathrm{a}$ & $58.6 \mathrm{a}$ & $0.49 \mathrm{a}$ \\
\hline Yangdao 6 & $\mathrm{Cd}$ & $3.69 \mathrm{~b}$ & $19.5 \mathrm{~b}$ & $58.9 \mathrm{~b}$ & $92.2 \mathrm{~b}$ & $56.5 \mathrm{a}$ & $0.50 \mathrm{a}$ \\
\hline 汕优 63 & CK & $6.59 \mathrm{a}$ & $32.6 \mathrm{a}$ & $96.9 \mathrm{a}$ & $153.0 \mathrm{a}$ & $86.8 \mathrm{a}$ & $0.52 \mathrm{a}$ \\
\hline Shanyou 63 & $\mathrm{Cd}$ & $6.23 \mathrm{a}$ & $31.8 \mathrm{a}$ & $93.8 \mathrm{a}$ & $145.0 \mathrm{a}$ & $88.4 \mathrm{a}$ & $0.51 \mathrm{a}$ \\
\hline 武运粳 7 号 & CK & $5.86 \mathrm{a}$ & $30.1 \mathrm{a}$ & $95.2 \mathrm{a}$ & $155.0 \mathrm{a}$ & $43.6 \mathrm{a}$ & $0.47 \mathrm{a}$ \\
\hline Wuyunjing 7 & $\mathrm{Cd}$ & $3.45 \mathrm{~b}$ & $17.2 \mathrm{~b}$ & $54.6 \mathrm{~b}$ & $85.1 \mathrm{~b}$ & $45.3 \mathrm{a}$ & $0.47 \mathrm{a}$ \\
\hline 扬粳 9538 & CK & $5.51 \mathrm{a}$ & $27.9 \mathrm{a}$ & $85.8 \mathrm{a}$ & $131.0 \mathrm{a}$ & $39.6 \mathrm{a}$ & $0.49 \mathrm{a}$ \\
\hline Yangjing 9538 & $\mathrm{Cd}$ & $4.89 \mathrm{~b}$ & $24.8 \mathrm{~b}$ & $79.3 \mathrm{a}$ & $122.0 \mathrm{a}$ & $37.8 \mathrm{a}$ & $0.48 \mathrm{a}$ \\
\hline
\end{tabular}

同一基因型(品种)内标以不同字母者表示 $\mathrm{Cd}$ 处理与对照 $(\mathrm{CK})$ 间在 $P=0.05$ 水平上差异显著。数据为 2 年的平均值。

Values within a column for a genotype followed by a different letter are significantly different between $\mathrm{Cd}$ treatment and $\mathrm{CK}$ at $P=0.05$. Data presented are averages between the two years. 
表 3 镉处理后水稻不同器官镉浓度及累积量

Table 3 Cadmium (Cd) concentration and accumulation in different organs of rice under Cd treatment

\begin{tabular}{|c|c|c|c|c|c|c|c|}
\hline \multirow{2}{*}{$\begin{array}{c}\text { 基因型 } \\
\text { Genotype }\end{array}$} & \multicolumn{2}{|c|}{ 根 Root } & \multicolumn{2}{|c|}{ 茎+叶 Stem + leaf } & \multicolumn{2}{|c|}{ 穗/籽粒 Panicle/grain } & \multirow{2}{*}{$\begin{array}{c}\text { 总累积量 } \\
\text { Total Cd } \\
\left(\mathrm{mg} \mathrm{pot}^{-1}\right)\end{array}$} \\
\hline & $\begin{array}{c}\text { 浓度 } \\
\text { Conc. } \\
\left(\mu \mathrm{g} \mathrm{g}^{-1}\right)\end{array}$ & $\begin{array}{c}\text { 累积量 } \\
\text { Accum. } \\
\left(\mathrm{mg} \mathrm{pot}^{-1}\right)\end{array}$ & $\begin{array}{c}\text { 浓度 } \\
\text { Conc. } \\
\left(\mu \mathrm{g} \mathrm{g}^{-1}\right)\end{array}$ & $\begin{array}{c}\text { 累积量 } \\
\text { Accum. } \\
\left(\mathrm{mg} \mathrm{pot}^{-1}\right)\end{array}$ & $\begin{array}{c}\text { 浓度 } \\
\text { Conc. } \\
\left(\mu \mathrm{g} \mathrm{g}^{-1}\right)\end{array}$ & $\begin{array}{c}\text { 累积量 } \\
\text { Accum. } \\
\left(\mathrm{mg} \mathrm{pot}^{-1}\right)\end{array}$ & \\
\hline \multicolumn{8}{|l|}{ 抽穗期 Heading } \\
\hline 扬稻 6 号 Yangdao 6 & $338.0 \mathrm{a}$ & $4.21 \mathrm{~d}$ & $14.87 \mathrm{a}$ & $0.76 \mathrm{c}$ & $1.29 \mathrm{a}$ & $0.010 \mathrm{c}$ & $4.98 \mathrm{c}$ \\
\hline 汕优 63 Shanyou 63 & $342.0 \mathrm{a}$ & $6.35 \mathrm{a}$ & $14.74 \mathrm{a}$ & $1.07 \mathrm{a}$ & $1.28 \mathrm{a}$ & $0.027 \mathrm{a}$ & $7.45 \mathrm{a}$ \\
\hline 武运粳 7 号 Wuyunjing 7 & $340.0 \mathrm{a}$ & $4.15 \mathrm{c}$ & $14.32 \mathrm{a}$ & $0.68 \mathrm{~d}$ & $1.25 \mathrm{a}$ & $0.009 \mathrm{c}$ & $4.84 \mathrm{c}$ \\
\hline 扬粳 9538 Yangjing 9538 & $336.0 \mathrm{a}$ & $5.47 \mathrm{~b}$ & $14.98 \mathrm{a}$ & $0.97 \mathrm{~b}$ & $1.26 \mathrm{a}$ & $0.018 \mathrm{~b}$ & $6.46 \mathrm{~b}$ \\
\hline \multicolumn{8}{|l|}{ 成熟期 Maturity } \\
\hline 扬稻 6 号 Yangdao 6 & $352.0 \mathrm{a}$ & $4.84 \mathrm{c}$ & $14.54 \mathrm{a}$ & $0.67 \mathrm{c}$ & $0.68 \mathrm{a}$ & $0.03 \mathrm{c}$ & $5.54 \mathrm{c}$ \\
\hline 武运粳 7 号 Wuyunjing 7 & $348.0 \mathrm{a}$ & $4.49 \mathrm{~d}$ & $14.22 \mathrm{a}$ & $0.64 \mathrm{c}$ & $0.69 \mathrm{a}$ & $0.03 \mathrm{c}$ & $5.16 \mathrm{c}$ \\
\hline 扬粳 9538 Yangjing 9538 & $350.0 \mathrm{a}$ & $5.78 \mathrm{~b}$ & $14.49 \mathrm{a}$ & $0.91 \mathrm{~b}$ & $0.66 \mathrm{a}$ & $0.04 \mathrm{~b}$ & $6.73 \mathrm{~b}$ \\
\hline
\end{tabular}

同一基因型(品种)内标以不同字母者表示 $\mathrm{Cd}$ 处理与对照 $(\mathrm{CK})$ 间在 $P=0.05$ 水平上差异显著。数据为 2 年的平均值。表 3 中 $\mathrm{Conc}$. 和 Accum. 分别为 Concentration 和 Accumulation 的缩写。

Values within a column for a genotype followed by a different letter are significantly different between Cd treatment and CK at $P=0.05$. Data presented are averages between the two years. Conc. and Accum. are the abbreviation of Concentration and Accumulation in Table 3, respectively.

\section{3 根系氧化力和叶片光合速率}

$\mathrm{Cd}$ 处理明显降低了生育前期的根系氧化力 (表 4)。随着生育进程, $\mathrm{Cd}$ 对根系活性(氧化力)的影响逐 渐减少。抽穗以后, 各品种的根系活性在 $\mathrm{Cd}$ 处理与 $\mathrm{CK}$ 间无显著差异。 $\mathrm{Cd}$ 处理后，自分蓝至拔节期 $\mathrm{Cd}$ 敏感基因型根系活性下降的幅度明显大于耐 $\mathrm{Cd}$ 基 因型。例如在分蓝初期, $\mathrm{Cd}$ 敏感基因型扬稻 6 号和 武运粳 7 号在 $\mathrm{Cd}$ 处理下的根系氧化力分别较 $\mathrm{CK}$ 下 降了 $52.5 \%$ 和 $49.1 \%$; 耐 $\mathrm{Cd}$ 基因型汕优 63 和扬粳 9538 在 $\mathrm{Cd}$ 处理下的根系氧化力分别较 $\mathrm{CK}$ 降低了

\section{$14.9 \%$ 和 $22.8 \%$ (表 4)。}

与根系氧化力的变化趋势相类似, $\mathrm{Cd}$ 处理后降 低了生育前中期的叶片光合速率(表 5)。随生育的进 程, $\mathrm{Cd}$ 对叶片光合速率的影响逐渐减小, 自抽穗以 后, 各品种叶片光合速率在 $\mathrm{Cd}$ 处理和 $\mathrm{CK}$ 间无显著 差异。分藥至拔节期 $\mathrm{Cd}$ 对叶片光合速率的影响, $\mathrm{Cd}$ 敏感基因型明显大于耐 $\mathrm{Cd}$ 基因型。再次表明 $\mathrm{Cd}$ 对 水稻生育的影响主要表现在前中期。因抽穗以后 $\mathrm{Cd}$ 对水稻生理性状的影响已不明显, 故以下仅报告抽 穗前的测定结果。

表 4 镉处理对水稻根系氧化力的影响

Table 4 Effect of cadmium (Cd) treatment on root oxidation activity of rice $\left(\mu \mathrm{g} \alpha-\mathrm{NA} \mathrm{g}^{-1} \mathrm{FW} \mathrm{h}^{-1}\right)$

\begin{tabular}{|c|c|c|c|c|c|c|c|}
\hline $\begin{array}{l}\text { 基因型 } \\
\text { Genotype }\end{array}$ & $\begin{array}{c}\text { 处理 } \\
\text { Treatment }\end{array}$ & $\begin{array}{c}\text { 分藍初期 } \\
\text { Early-tillering }\end{array}$ & 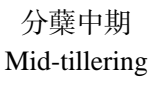 & $\begin{array}{l}\text { 拔节期 } \\
\text { Jointing }\end{array}$ & $\begin{array}{l}\text { 抽穗期 } \\
\text { Heading }\end{array}$ & $\begin{array}{c}\text { 乳熟期 } \\
\text { Milky stage }\end{array}$ & $\begin{array}{c}\text { 蜡熟期 } \\
\text { Waxy stage }\end{array}$ \\
\hline 扬稻 6 号 & $\mathrm{CK}$ & $132.0 \mathrm{a}$ & $138.0 \mathrm{a}$ & $113.0 \mathrm{a}$ & $105.0 \mathrm{a}$ & $87.6 \mathrm{a}$ & $45.9 \mathrm{a}$ \\
\hline Yangdao 6 & $\mathrm{Cd}$ & $70.9 \mathrm{~b}$ & $62.8 \mathrm{~b}$ & $83.7 \mathrm{~b}$ & $101.0 \mathrm{a}$ & $85.3 \mathrm{a}$ & $47.8 \mathrm{a}$ \\
\hline 汕优 63 & $\mathrm{CK}$ & $126.0 \mathrm{a}$ & $132.0 \mathrm{a}$ & $107.0 \mathrm{a}$ & $98.6 \mathrm{a}$ & $78.9 \mathrm{a}$ & $36.7 \mathrm{a}$ \\
\hline Shanyou 63 & $\mathrm{Cd}$ & $106.0 \mathrm{~b}$ & $127.0 \mathrm{a}$ & $105.0 \mathrm{a}$ & $99.3 \mathrm{a}$ & $78.2 \mathrm{a}$ & $37.4 \mathrm{a}$ \\
\hline 武运粳 7 号 & CK & $138.0 \mathrm{a}$ & $143.0 \mathrm{a}$ & $120.0 \mathrm{a}$ & $113.0 \mathrm{a}$ & $88.6 \mathrm{a}$ & $50.3 \mathrm{a}$ \\
\hline Wuyunjing 7 & $\mathrm{Cd}$ & $72.4 \mathrm{~b}$ & $58.9 \mathrm{~b}$ & $95.5 \mathrm{~b}$ & $107.0 \mathrm{a}$ & $89.5 \mathrm{a}$ & $48.9 \mathrm{a}$ \\
\hline 扬粳 9538 & CK & $132.0 \mathrm{a}$ & $141.0 \mathrm{a}$ & $126.0 \mathrm{a}$ & $112.0 \mathrm{a}$ & $85.3 \mathrm{a}$ & $45.6 \mathrm{a}$ \\
\hline Yangjing 9538 & $\mathrm{Cd}$ & $113.0 \mathrm{~b}$ & $134.0 \mathrm{a}$ & $124.0 \mathrm{a}$ & $115.0 \mathrm{a}$ & $84.2 \mathrm{a}$ & $43.8 \mathrm{a}$ \\
\hline
\end{tabular}

同一基因型(品种)内标以不同字母者表示 $\mathrm{Cd}$ 处理与对照 $(\mathrm{CK})$ 间在 $P=0.05$ 水平上差异显著。数据为 2 年的平均值。

Values within a column for a genotype followed by a different letter are significantly different between Cd treatment and CK at $P=0.05$. Data presented are averages between the two years. 
2.4 活性氧含量与抗氧化酶活性

$\mathrm{Cd}$ 处理显著增加了 $\mathrm{Cd}$ 敏感基因型在分苜期和 拔节期叶片中超氧自由基 $\left(\mathrm{O}_{2}^{-}\right)$和过氧化氢 $\left(\mathrm{H}_{2} \mathrm{O}_{2}\right)$ 含 量, 对耐 $\mathrm{Cd}$ 基因型叶片中 $\mathrm{O}_{2}^{-}$和 $\mathrm{H}_{2} \mathrm{O}_{2}$ 含量无显著影
响(表 6)。

$\mathrm{Cd}$ 处理增强了各基因型在分蓝期和拔节期的 叶片超氧化物歧化酶(SOD) 和过氧化氢酶(CAT)活 性(表 7)。与 $\mathrm{CK}$ 相比, $\mathrm{Cd}$ 处理下耐 $\mathrm{Cd}$ 基因型叶片

表 5 镉处理对水稻叶片光合速率的影响

Table 5 Effect of cadmium (Cd) treatment on photosynthetic rate in rice leaves $\left(\mu \mathrm{mol} \mathrm{CO}_{2} \mathrm{~m}^{-2} \mathrm{~s}^{-1}\right)$

\begin{tabular}{|c|c|c|c|c|c|c|c|}
\hline 基因型 & 处理 & 分藮初期 & 分藍中期 & 拔节期 & 抽穗期 & 乳熟期 & 蜡熟期 \\
\hline Genotype & Treatment & Early-tillering & Mid-tillering & Jointing & Heading & Milky stage & Waxy stage \\
\hline 扬稻 6 号 & $\mathrm{CK}$ & $17.9 \mathrm{a}$ & $18.5 \mathrm{a}$ & $18.9 \mathrm{a}$ & $20.1 \mathrm{a}$ & $15.4 \mathrm{a}$ & $7.64 \mathrm{a}$ \\
\hline Yangdao 6 & $\mathrm{Cd}$ & $8.51 \mathrm{~b}$ & $7.94 \mathrm{~b}$ & $13.5 \mathrm{~b}$ & $18.9 \mathrm{a}$ & $14.6 \mathrm{a}$ & $7.59 \mathrm{a}$ \\
\hline 汕优 63 & $\mathrm{CK}$ & $16.8 \mathrm{a}$ & $17.5 \mathrm{a}$ & $17.7 \mathrm{a}$ & $19.7 \mathrm{a}$ & $11.2 \mathrm{a}$ & $5.23 \mathrm{a}$ \\
\hline Shanyou 63 & $\mathrm{Cd}$ & $13.7 \mathrm{~b}$ & $16.3 \mathrm{a}$ & $16.1 \mathrm{a}$ & $19.5 \mathrm{a}$ & $11.5 \mathrm{a}$ & $5.35 \mathrm{a}$ \\
\hline Wuyunjing 7 & $\mathrm{Cd}$ & $9.42 \mathrm{~b}$ & $8.75 \mathrm{~b}$ & $14.1 \mathrm{~b}$ & $20.6 \mathrm{a}$ & $14.8 \mathrm{a}$ & $8.39 \mathrm{a}$ \\
\hline 扬粳 9538 & $\mathrm{CK}$ & $16.7 \mathrm{a}$ & $17.6 \mathrm{a}$ & $18.4 \mathrm{a}$ & 20.9 a & $14.9 \mathrm{a}$ & $7.26 \mathrm{a}$ \\
\hline Yangjing 9538 & $\mathrm{Cd}$ & $12.9 \mathrm{~b}$ & $15.3 \mathrm{a}$ & $17.3 \mathrm{a}$ & $19.6 \mathrm{a}$ & $14.5 \mathrm{a}$ & $7.27 \mathrm{a}$ \\
\hline
\end{tabular}

同一基因型(品种)内标以不同字母者表示 $\mathrm{Cd}$ 处理与对照(CK)间在 $P=0.05$ 水平上差异显著。数据为 2 年的平均值。

Values within a column for a genotype followed by a different letter are significantly different between Cd treatment and CK at $P=0.05$. Data are averages between the two years.

表 6 镉处理对水稻叶片超氧自由基 $\left(\mathrm{O}_{2}^{-}\right)$和过氧化氢 $\left(\mathrm{H}_{2} \mathrm{O}_{2}\right)$ 含量的影响

Table 6 Effect of cadmium $(\mathrm{Cd})$ treatment on contents of superoxide radical $\left(\mathrm{O}_{2}^{-}\right)$and hydrogen peroxide $\left(\mathrm{H}_{2} \mathrm{O}_{2}\right)$ in rice leaves $\left(\right.$ nmol $\left.\mathrm{g}^{-1} \mathrm{FW}\right)$

\begin{tabular}{|c|c|c|c|c|c|c|c|}
\hline \multirow{3}{*}{$\begin{array}{c}\text { 基因型 } \\
\text { Genotype }\end{array}$} & \multirow{3}{*}{$\begin{array}{c}\text { 处理 } \\
\text { Treatment }\end{array}$} & & & & \multicolumn{3}{|c|}{$\mathrm{H}_{2} \mathrm{O}_{2}$} \\
\hline & & 分藍中期 & 拔节期 & 抽穗期 & 分藍中期 & 拔节期 & 抽穗期 \\
\hline & & Mid-tillering & Jointing & Heading & Mid-tillering & Jointing & Heading \\
\hline 扬稻 6 号 & $\mathrm{CK}$ & $3.48 \mathrm{~b}$ & $3.52 \mathrm{~b}$ & $3.17 \mathrm{a}$ & $35.9 \mathrm{~b}$ & $37.4 \mathrm{~b}$ & $41.2 \mathrm{a}$ \\
\hline Yangdao 6 & $\mathrm{Cd}$ & $6.87 \mathrm{a}$ & $5.49 \mathrm{a}$ & $3.08 \mathrm{a}$ & $63.8 \mathrm{a}$ & $50.6 \mathrm{a}$ & $43.6 \mathrm{a}$ \\
\hline 汕优 63 & $\mathrm{CK}$ & $3.51 \mathrm{a}$ & $3.63 \mathrm{a}$ & $3.29 \mathrm{a}$ & $37.5 \mathrm{a}$ & $39.6 \mathrm{a}$ & $42.5 \mathrm{a}$ \\
\hline Shanyou 63 & $\mathrm{Cd}$ & $3.85 \mathrm{a}$ & $3.71 \mathrm{a}$ & $3.32 \mathrm{a}$ & $40.3 \mathrm{a}$ & $41.5 \mathrm{a}$ & $41.8 \mathrm{a}$ \\
\hline 武运粳 7 号 & $\mathrm{CK}$ & $3.32 \mathrm{~b}$ & $3.57 \mathrm{~b}$ & $3.43 \mathrm{a}$ & $32.7 \mathrm{~b}$ & $35.5 \mathrm{~b}$ & 39.9 a \\
\hline Wuyunjing 7 & $\mathrm{Cd}$ & $6.14 \mathrm{a}$ & $5.18 \mathrm{a}$ & $3.36 \mathrm{a}$ & $56.9 \mathrm{a}$ & $48.3 \mathrm{a}$ & $40.5 \mathrm{a}$ \\
\hline 扬粳 9538 & $\mathrm{CK}$ & $3.35 \mathrm{a}$ & $3.44 \mathrm{a}$ & $3.28 \mathrm{a}$ & $34.5 \mathrm{a}$ & $36.3 \mathrm{a}$ & $37.5 \mathrm{a}$ \\
\hline Yangjing 9538 & $\mathrm{Cd}$ & $3.76 \mathrm{a}$ & $3.53 \mathrm{a}$ & $3.30 \mathrm{a}$ & $35.9 \mathrm{a}$ & $37.2 \mathrm{a}$ & $38.1 \mathrm{a}$ \\
\hline
\end{tabular}

同一基因型(品种)内标以不同字母者表示 $\mathrm{Cd}$ 处理与对照(CK)间在 $P=0.05$ 水平上差异显著。数据为 2 年的平均值。

Values within a column for a genotype followed by a different letter are significantly different between Cd treatment and CK at $P=0.05$. Data are averages between the two years.

表 7 镉处理对水稻叶片超氧化物歧化酶(SOD)和过氧化氢酶(CAT)活性的影响

Table 7 Effect of cadmium (Cd) treatment on activities of superoxide dismutase (SOD) and catalase (CAT) in rice leaves

\begin{tabular}{|c|c|c|c|c|c|c|c|}
\hline \multirow{3}{*}{$\begin{array}{c}\text { 基因型 } \\
\text { Genotype }\end{array}$} & \multirow{3}{*}{$\begin{array}{c}\text { 处理 } \\
\text { Treatment }\end{array}$} & \multicolumn{3}{|c|}{$\operatorname{SOD}\left(\mathrm{Ug} \mathrm{g}^{-1} \mathrm{FW} \mathrm{min}^{-1}\right)$} & \multicolumn{3}{|c|}{$\mathrm{CAT}\left(\mathrm{mg} \mathrm{H}_{2} \mathrm{O}_{2} \mathrm{~g}^{-1} \mathrm{FW} \min ^{-1}\right)$} \\
\hline & & 分藍中期 & 拔节期 & 抽穗期 & 分藍中期 & 拔节期 & 抽穗期 \\
\hline & & Mid-tillering & Jointing & Heading & Mid-tillering & Jointing & Heading \\
\hline 扬稻 6 号 & $\mathrm{CK}$ & $387 \mathrm{a}$ & $369 \mathrm{a}$ & $383 \mathrm{a}$ & $87.2 \mathrm{a}$ & $79.5 \mathrm{a}$ & $86.4 \mathrm{a}$ \\
\hline Yangdao 6 & $\mathrm{Cd}$ & 396 a & $375 \mathrm{a}$ & $384 \mathrm{a}$ & $91.5 \mathrm{a}$ & $84.6 \mathrm{a}$ & $85.3 \mathrm{a}$ \\
\hline 汕优 63 & $\mathrm{CK}$ & $384 \mathrm{~b}$ & $362 \mathrm{~b}$ & $376 \mathrm{a}$ & $85.3 \mathrm{~b}$ & $75.3 \mathrm{~b}$ & 87.8 a \\
\hline Shanyou 63 & $\mathrm{Cd}$ & $425 \mathrm{a}$ & $383 \mathrm{a}$ & $375 \mathrm{a}$ & $98.6 \mathrm{a}$ & $86.9 \mathrm{a}$ & $88.6 \mathrm{a}$ \\
\hline 武运粳 7 号 & $\mathrm{CK}$ & $368 \mathrm{~b}$ & $355 \mathrm{a}$ & $397 \mathrm{a}$ & $85.4 \mathrm{a}$ & 80.6 a & $90.5 \mathrm{a}$ \\
\hline Wuyunjing 7 & $\mathrm{Cd}$ & $379 \mathrm{a}$ & $363 \mathrm{a}$ & $392 \mathrm{a}$ & $88.8 \mathrm{a}$ & $84.8 \mathrm{a}$ & $91.8 \mathrm{a}$ \\
\hline 扬粳 9538 & $\mathrm{CK}$ & $362 \mathrm{~b}$ & $362 \mathrm{~b}$ & $381 \mathrm{a}$ & $86.2 \mathrm{~b}$ & $81.7 \mathrm{~b}$ & $88.4 \mathrm{a}$ \\
\hline Yangjing 9538 & $\mathrm{Cd}$ & $394 \mathrm{a}$ & $384 \mathrm{a}$ & $378 \mathrm{a}$ & $97.4 \mathrm{a}$ & $93.5 \mathrm{a}$ & $89.3 \mathrm{a}$ \\
\hline
\end{tabular}

同一基因型(品种)内标以不同字母者表示 $\mathrm{Cd}$ 处理与对照(CK)间在 $P=0.05$ 水平上差异显著。数据为 2 年的平均值。

Values within a column for a genotype followed by a different letter are significantly different between $\mathrm{Cd}$ treatment and $\mathrm{CK}$ at $P=0.05$. Data are averages between the two years. 
SOD 和 CAT 活性的增加达到显著水平, 而 $\mathrm{Cd}$ 敏感 基因型则 $\mathrm{Cd}$ 处理与 $\mathrm{CK}$ 的差异不显著。说明耐 $\mathrm{Cd}$ 基因型具有较强的抗氧化保护系统, 在 $\mathrm{Cd}$ 胁迫下有 较强的清除体内活性氧自由基的能力。

\section{$2.5 \mathrm{ABA}$ 含量和乙烯释放速率}

$\mathrm{Cd}$ 处理对各基因型叶片 $\mathrm{ABA}$ 含量无显著影响(表 8)。在 $\mathrm{Cd}$ 处理下, 耐 $\mathrm{Cd}$ 基因型叶片乙烯释放速率与 $\mathrm{CK}$ 亦无显著差异, 但 $\mathrm{Cd}$ 处理显著增加了 $\mathrm{Cd}$ 敏感基
因型分蝀期和拔节期的叶片乙烯释放速率(表 8)。

与叶片乙烯释放速率的测定结果相类似, $\mathrm{Cd}$ 处理 下 $\mathrm{Cd}$ 敏感基因型根系伤流液中的 ACC 浓度较对照显 著增加，耐 $\mathrm{Cd}$ 基因型 $\mathrm{ACC}$ 浓度则在 $\mathrm{Cd}$ 处理和 $\mathrm{CK}$ 间 无显著差异(图 2)。相关分析表明, 根系伤流液 ACC 浓度与叶片乙烯释放速率高度正相关 $\left(r=0.99^{* * *}\right)$ 。说明 $\mathrm{Cd}$ 敏感基因型在 $\mathrm{Cd}$ 处理下叶片乙烯释放速率高, 与 根系乙烯合成前体一 $\mathrm{ACC}$ 合成量多有关。

表 8 镉处理对水稻叶片脱落酸(ABA)含量和乙烯 $(\mathbf{E T H})$ 释放速率的影响

Table 8 Effect of cadmium (Cd) treatment on ABA content and ethylene (ETH) evolution rate of rice leaves

\begin{tabular}{|c|c|c|c|c|c|c|c|}
\hline \multirow{3}{*}{$\begin{array}{c}\text { 基因型 } \\
\text { Genotype }\end{array}$} & \multirow{3}{*}{$\begin{array}{c}\text { 处理 } \\
\text { Treatment }\end{array}$} & \multicolumn{3}{|c|}{$\mathrm{ABA}\left(\mathrm{ng} \mathrm{g}^{-1} \mathrm{FW}\right)$} & \multicolumn{3}{|c|}{ ETH $\left(\mathrm{pmol} \mathrm{g}^{-1} \mathrm{FW} \mathrm{h}^{-1}\right)$} \\
\hline & & 分睬中期 & 拔节期 & 抽穗期 & 分藥中期 & 拔节期 & 抽穗期 \\
\hline & & Mid-tillering & Jointing & Heading & Mid-tillering & Jointing & Heading \\
\hline 扬稻 6 号 & $\mathrm{CK}$ & $75.3 \mathrm{a}$ & $83.5 \mathrm{a}$ & $68.7 \mathrm{a}$ & $98.6 \mathrm{~b}$ & $101 \mathrm{~b}$ & $76.4 \mathrm{a}$ \\
\hline Yangdao 6 & $\mathrm{Cd}$ & $71.8 \mathrm{a}$ & $80.6 \mathrm{a}$ & $67.9 \mathrm{a}$ & $153.0 \mathrm{a}$ & $138 \mathrm{a}$ & $79.3 \mathrm{a}$ \\
\hline 汕优 63 & CK & $73.2 \mathrm{a}$ & $75.7 \mathrm{a}$ & $65.4 \mathrm{a}$ & $89.6 \mathrm{a}$ & $105 \mathrm{a}$ & $78.5 \mathrm{a}$ \\
\hline Shanyou 63 & $\mathrm{Cd}$ & $76.7 \mathrm{a}$ & $78.3 \mathrm{a}$ & $64.8 \mathrm{a}$ & $93.4 \mathrm{a}$ & $107 \mathrm{a}$ & $74.3 \mathrm{a}$ \\
\hline 武运粳 7 号 & CK & $68.9 \mathrm{a}$ & $72.5 \mathrm{a}$ & $56.8 \mathrm{a}$ & $87.5 \mathrm{~b}$ & $113 \mathrm{~b}$ & $69.6 \mathrm{a}$ \\
\hline Wuyunjing 7 & $\mathrm{Cd}$ & $66.3 \mathrm{a}$ & $70.1 \mathrm{a}$ & $57.2 \mathrm{a}$ & $135.0 \mathrm{a}$ & 149 a & $64.0 \mathrm{a}$ \\
\hline 扬粳 9538 & CK & $70.1 \mathrm{a}$ & $73.4 \mathrm{a}$ & 58.9 a & $83.8 \mathrm{a}$ & $105 \mathrm{a}$ & $65.1 \mathrm{a}$ \\
\hline Yangjing 9538 & $\mathrm{Cd}$ & $72.7 \mathrm{a}$ & $75.7 \mathrm{a}$ & $57.6 \mathrm{a}$ & $85.4 \mathrm{a}$ & $103 \mathrm{a}$ & $67.4 \mathrm{a}$ \\
\hline
\end{tabular}

同一基因型(品种)内标以不同字母者表示 $\mathrm{Cd}$ 处理与对照 $(\mathrm{CK})$ 间在 $P=0.05$ 水平上差异显著。数据为 2 年的平均值。

Values within a column for a genotype followed by a different letter are significantly different between Cd treatment and CK at $P=0.05$. Data are averages between the two years.
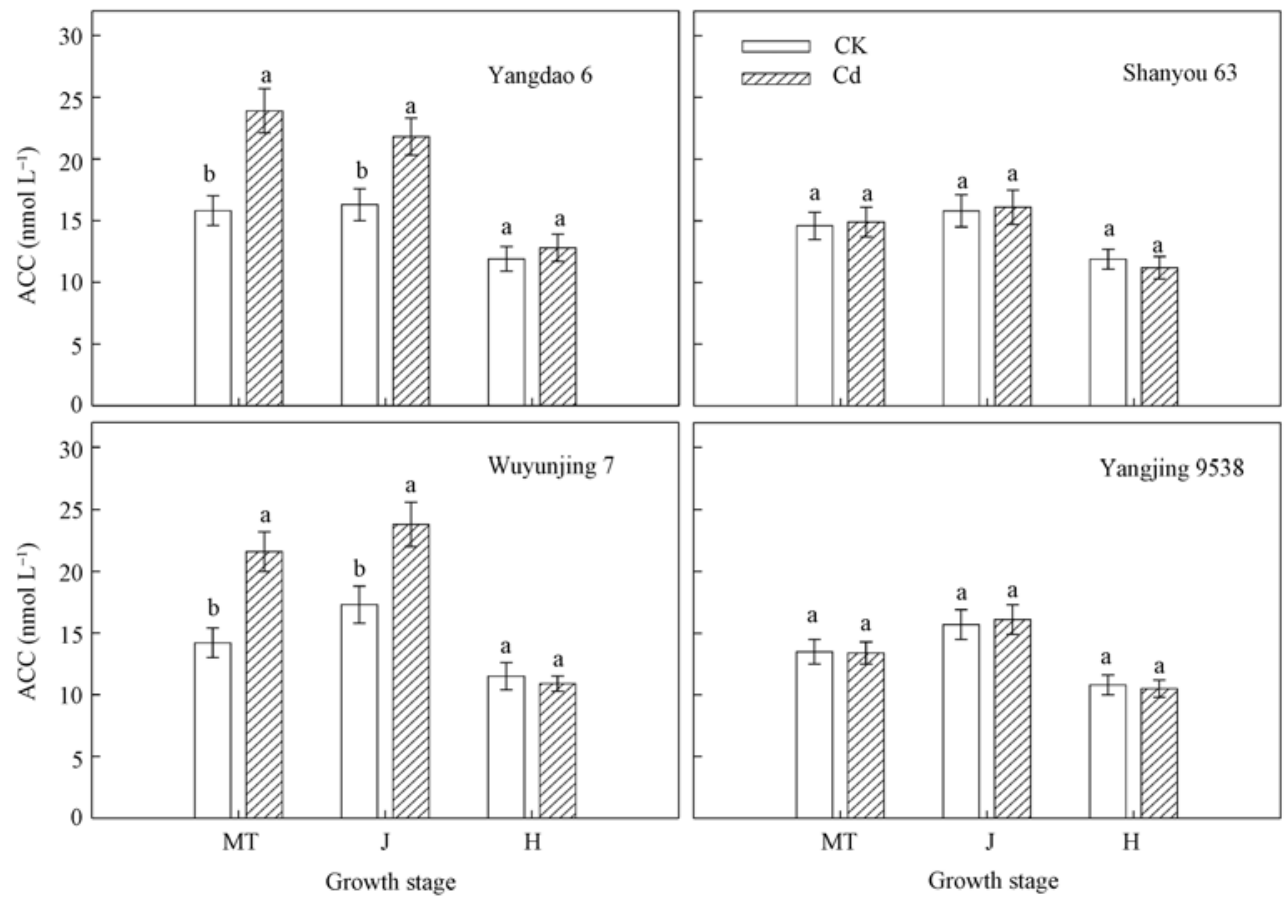

图 2 Cd 处理对水稻根系伤流液中 1-氨基环丙烷-1-羧酸(ACC)浓度的影响

Fig. 2 Effect of Cd treatment on 1-aminocylopropane-1- carboxylic acid (ACC) concentration in root bleedings of rice 同一测定期柱上标以不同字母者表示 $\mathrm{Cd}$ 处理与对照 $(\mathrm{CK})$ 间在 $P=0.05$ 水平上差异显著。 $\mathrm{MT}$ : 分蔝中期; $\mathrm{J}$ : 拔节期; $\mathrm{H}$ : 抽穗期。数据为 2 年的平均值。

Bar superscripted followed by different letters within the same measure date are significantly different between $\mathrm{Cd}$ treatment and $\mathrm{CK}$ at $P=0.05$. MT: Mid-tillering; J: Jointing; H: Heading. Data are averages between the two years. 


\section{3 讨论}

本研究表明, $\mathrm{Cd}$ 对水稻产量的影响在基因型间 存在很大差异。在 $\mathrm{Cd}$ 胁迫下, 耐 $\mathrm{Cd}$ 基因型的相对 产量 $[\mathrm{Cd}$ 处理产量/对照(未加 $\mathrm{Cd}$ )产量]显著高于 $\mathrm{Cd}$ 敏感基因型。在 $\mathrm{Cd}$ 胁迫下由于分藥的抑制造成穗数 的不足和每穗颖花数的减少是 $\mathrm{Cd}$ 敏感基因型减产 的主要原因。说明 $\mathrm{Cd}$ 对水稻特别是 $\mathrm{Cd}$ 敏感基因型 的毒害作用主要发生在生育前中期。在生育中后期 (抽穗以后), $\mathrm{Cd}$ 对水稻生长的影响基本消失, 因而 结实率和粒重保持在一个较高的水平。有关 $\mathrm{Cd}$ 对水 稻生长发育的影响在不同生育期存在差异的原因, 目前尚不清楚。有研究报道, $\mathrm{Cd}$ 对植物产生毒害作 用的一个重要机理, 就是 $\mathrm{Cd}$ 与蛋白质结合, 通过改 变硫氢键等方式使蛋白质变性, 从而阻碍植物的正 常生长发育 ${ }^{[20-21]}$ 。在生育前中期, 稻苗的含氮量较 高, 发根、分藥以及穗分化需要较高的含氮化合物 的代谢 ${ }^{[22]}$ 。Cd 容易对这些含氮化合物特别是蛋白质 产生毒害作用, 从而抑制水稻的生育。在生育后期, 水稻主要以碳代谢或碳的累积为主, 因而, 此期 $\mathrm{Cd}$ 对水稻籽粒灌浆和充实影响很小。另一种可能是, 在生育前期水稻对 $\mathrm{Cd}$ 的适应性能力较弱, 因而 $\mathrm{Cd}$ 对水稻生长发育的毒害性较大; 随生育进程, 稻株 对 $\mathrm{Cd}$ 的适应性逐渐增强, $\mathrm{Cd}$ 对水稻生长发育的毒害 性减弱。上述分析均说明, 生育前中期稻苗对 $\mathrm{Cd}$ 适 应能力的大小直接决定了水稻基因型耐 $\mathrm{Cd}$ 性的强 弱。鉴此, 笔者建议可将相对分藥数 $(\mathrm{Cd}$ 处理分藥数 /对照分萺数) 和相对每穗颖花数 $(\mathrm{Cd}$ 处理每穗颖花 数/对照每穗颖花数)作为选择耐 $\mathrm{Cd}$ 水稻品种的农艺 指标。

前人曾对 $\mathrm{Cd}$ 的毒害机理进行了较多的研究, 认 识到 $\mathrm{Cd}$ 胁迫下活性氧自由基的过多产生、抗氧化保 护酶活性的降低、膜和脱氧核糖核酸(DNA)损伤是 $\mathrm{Cd}$ 对植物产生毒害的重要生理机制 ${ }^{[23-25]}$ 。但对不同 耐 $\mathrm{Cd}$ 基因型水稻的生理生化缺乏比较分析。本试验 观察到, 生育前中期的根系氧化力、叶片光合速率、 SOD 和 CAT 活性的相对值 ( $\mathrm{Cd}$ 处理/对照), 耐 $\mathrm{Cd}$ 基 因型均高于 $\mathrm{Cd}$ 敏感基因型, 而叶片 $\mathrm{O}_{2}^{-}$和 $\mathrm{H}_{2} \mathrm{O}_{2}$ 含量 的相对值 ( $\mathrm{Cd}$ 处理/对照), 则耐 $\mathrm{Cd}$ 基因型低于 $\mathrm{Cd}$ 敏 感基因型。说明根系活性和植株体内抗氧化系统能 力强是耐 $\mathrm{Cd}$ 基因型 $\mathrm{Cd}$ 毒害轻、相对分藥数和相对 每穗颖花数多的重要生理基础。

一般认为, $\mathrm{ABA}$ 和乙烯是植物对生物和非生物
逆境作出响应的两类激素, 因而称其为逆境激素 (stress hormones) ${ }^{[26-27]}$ 。本试验观察到, 在 $\mathrm{Cd}$ 胁迫下 各供试材料叶片 $\mathrm{ABA}$ 含量与未加 $\mathrm{Cd}$ 的对照没有显 著差异, 推测 $\mathrm{Cd}$ 胁迫可能与干旱胁迫等不同, 不会 引起稻株体内 $\mathrm{ABA}$ 的明显变化。 $\mathrm{Cd}$ 对水稻乙烯的 产生，在基因型间存在很大差异，即在 $\mathrm{Cd}$ 胁迫下， $\mathrm{Cd}$ 敏感基因型根系伤流液中的 ACC 浓度和叶片乙 烯释放速率显著增加, 耐 $\mathrm{Cd}$ 基因型则在 $\mathrm{Cd}$ 处理和 $\mathrm{CK}$ 间无显著差异。有研究报道, 在逆境条件下植 物体内乙烯可作为信号传导促进活性氧系统 (ROS) 的生成，而 ROS 可以导致蛋白质和核酸的降解、酯 膜氧化和膜的损伤 ${ }^{[28-30]}$ 。由此推测, 在 $\mathrm{Cd}$ 胁迫下, 耐 $\mathrm{Cd}$ 基因型与 $\mathrm{Cd}$ 敏感基因型在活性氧自由基生成 和抗氧化酶活性上存在着差异, 可能与稻株体内乙 烯生成能力有密切关系。可认为乙烯合成少、抗氧 化保护系统能力强是水稻耐 $\mathrm{Cd}$ 基因型的重要生理 特征。

有研究认为, 一些根系活性强、产量较高的杂 交稻或高产品种, 其对 $\mathrm{Cd}$ 的吸收能力强, 在植株各 器官的累积量多 ${ }^{[1,31]}$ 。本研究则表明: 耐 $\mathrm{Cd}$ 性有明 显差异的两类基因型, 尽管在 $\mathrm{Cd}$ 胁迫下根系氧化 力、干物质重和产量存在明显的差异, 各器官 $\mathrm{Cd}$ 的 累积量耐 $\mathrm{Cd}$ 基因型也显著高于 $\mathrm{Cd}$ 敏感基因型, 但 各器官 $\mathrm{Cd}$ 的浓度在各基因型间均无显著差异。说明 单位产品器官 $\mathrm{Cd}$ 的吸收量与基因型的物质生产能 力并没有必然联系。一些高产基因型(品种)可能在产 品器官(如籽粒)里总的 $\mathrm{Cd}$ 累积量较高, 但单位籽粒 重量的 $\mathrm{Cd}$ 吸收量并不一定高。这一结果对于人们选 用或选育高产和 $\mathrm{Cd}$ 安全品种有积极的意义。一方面, 选用或选育 $\mathrm{Cd}$ 安全(稻米中 $\mathrm{Cd}$ 浓度较低)的品种, 并不一定要以牺牲产量为代价; 另一方面, 一般产 量高的品种, 其籽粒和稻草从土壤中带走的 Cd 也多, 这将有利于 $\mathrm{Cd}$ 污染土壤的修复。

\section{4 结论}

重金属 $\mathrm{Cd}$ 对水稻产量的影响在基因型间存在 很大差异, 单位产品器官 $\mathrm{Cd}$ 的吸收量与基因型的耐 $\mathrm{Cd}$ 性及物质生产能力没有必然联系, $\mathrm{Cd}$ 胁迫造成穗 数不足和每穗颖花数减少是 $\mathrm{Cd}$ 敏感基因型减产的 主要原因。在 $\mathrm{Cd}$ 胁迫下生育前中期分藥发生和颖花 分化多、根系活力和叶片抗氧化保护系统能力强及 乙烯合成少是耐 $\mathrm{Cd}$ 基因型水稻的主要农艺和生理 特征。 


\section{References}

[1] Hu H, Wang J, Fang W, Yuan J, Yang Z. Cadmium accumulation in different rice cultivars and screening for pollution-safe cultivars of rice. Sci Total Environ, 2006, 370: 302-309

[2] Zhao Q-G(赵其国), Zhou B-Z(周炳中), Yang H(杨浩). Studies on environment quality and safe problems in agriculture in $\mathrm{Ji}$ angsu province. Soil (土壤), 2002, 1: 1-8 (in Chinese)

[3] Wang K-R(王凯荣). Comparative study on Cd phytotoxicity to different genes of rice. Rural Ecol-Environ (农村生态环境), 1996, 12(3): 18-23 (in Chinese with English abstract)

[4] Gu J-G(顾继光), Zhou Q-X(周启星). Cleaning up through phytoremediation: a review of Cd contaminated soils. Ecol Sci (生态 科学), 2002, 21(4): 352-456 (in Chinese with English abstract)

[5] Li K-Q(李坤权), Liu J-G(刘建国), Lu X-L(陆小龙), Yang $\mathrm{J}-\mathrm{C}$ (杨建昌), Zhu Q-S(朱庆森). Uptake and distribution of cadmium in different rice cultivars. J Agron-Environ Sci (农业环境 科学学报), 2003, 22(5): 529-532 (in Chinese with English abstract)

[6] Wu Q-T(吴启堂), Chen L(陈卢), Wang G-S(王广寿). Differences on Cd uptake and accumulation among rice cultivars and its mechanism. Acta Ecol Sin (生态学报), 1999, 19(1): 104-107 (in Chinese with English abstract)

[7] Zhao B-H(赵步洪), Zhang H-X(张洪熙), Xi L-L(奚岭林), Zhu Q-S (朱庆森), Yang J-C (杨建昌). Concentrations and accumulation of cadmium in different organs of hybrid rice. Chin J Rice Sci (中国水稻科学), 2006, 20(3): 306-312 (in Chinese with English abstract)

[8] Wu F B, Dong J, Jia G X, Zheng S J, Zhang G P. Genotypic difference in the responses of seedling growth and $\mathrm{Cd}$ toxicity in rice (Oryza sativa L.). Agric Sci China, 2006, 5: 68-76

[9] Juwarkar A A, Nair A, Dubey K V, Singh S K, Devotta S. Biosurfactant technology for remediation of cadmium and lead contaminated soils. Chemosphere, 2007, 68: 1996-2002

[10] Pagliano C, Raviolo M, Vecchia F D, Gabbrielli R, Gonnelli C, Rascio N, Barbato R, Rocca N L. Evidence for PS II donor-side damage and photoinhibition induced by cadmium treatment on rice (Oryza sativa L.). J Photochem Photobiol B: Biology, 2006, 84: 70-78

[11] Liu J G, Liang J S, Li K Q, Zhang Z J, Yu BY, Lu X L, Yang J C, Zhu Q S. Correlations between cadmium and mineral nutrients in absorption and accumulation in various genotypes of rice under cadmium stress. Chemosphere, 2003, 52: 1467-1473

[12] Xi L-L(奚岭林). Effects of Cadmium and Lead on the Grain Yield and Quality of Rice and Their Distributions in the Plants. MS Dissertation of Yangzhou University, 2006. pp 20-35(in Chinese with English abstract)

[13] Srivalli B, Sharma G, Khanna-chopra R. Antioxidative defense system in an upland rice cultivar subjected to increasing intensity of water stress followed by recovery. Physiol Plant, 2003, 119: 503-512

[14] He Z-P(何钟佩). Experimental Guidance on Chemical Control in Crop Plants (农作物化学控制试验指导). Beijing: Beijing Agricultural University Press, 1993. pp 60-68 (in Chinese)

[15] Bollmark M, Kubat B, Eliasson L. Variations in endogenous cytokinin content during adventitious root formation in pea cuttings. J Plant Physiol, 1988, 132: 262-265

[16] Yang J, Zhang J, Wang Z, Liu K, Wang P. Post-anthesis develop- ment of inferior and superior spikelets in rice in relation to abscisic acid and ethylene. J Exp Bot, 2006, 57: 149-160

[17] Yang J-C(杨建昌), Chang E-H(常二华), Tang C(唐成), Zhang $\mathrm{H}$ (张耗), Wang Z-Q(王志琴). Relationships of ethylene evolution rate and 1-aminocylopropane-1-carboxylic acid concentration in grains during filling period with appearance quality of rice. Chin J Rice Sci (中国水稻科学), 2007, 21(1): 77-83 (in Chinese with English abstract)

[18] Yang J-C(杨建昌), Wang Z-Q(王志琴), Zhu Q-S(朱庆森). Effect of nitrogen nutrient on rice yield and its physiological mechanism under different status of soil moisture. Sci Agric Sin (中国农业科 学), 1996, 29(4): 58-66 (in Chinese with English abstract)

[19] Yoshida S, Shioya S. Photosynthesis of rice plant under water stress. Soil Sci Plant Nutr, 1975, 21: 169-180

[20] Aina R, Labra M, Fumagalli P, Vannini C, Marsoni M, Cucchi U, Bracale M, Sgorbati S, Citterio S. Thiol-peptide level and proteomic changes in response to cadmium toxicity in Oryza sativa L. roots. Environ Exp Bot, 2007, 59: 381-392

[21] Lin A J, Zhang X H, Chen M, Cao Q. Oxidative stress and DNA damages induced by cadmium accumulation. J Environ Sci, 2007, 19: $596-602$

[22] Murata Y, Matsushima S. Rice. In: Evans L T ed. Crop Physiology. Cambridge: Cambridge University Press, 1975. pp 75-99

[23] Smeets K, Cuypers A, Lambrechts A, Semane B, Hoet P, Laere A $\mathrm{V}$, Vangronsveld J. Induction of oxidative stress and antioxidative mechanisms in Phaseolus vulgaris after $\mathrm{Cd}$ application. Plant Physiol Biochem, 2005, 43: 437-444

[24] Nouairi I, Ammar W B, Youssef N B, Daoud D B M, Ghorbal M H, Zarrouk M. Comparative study of cadmium effects on membrane lipid composition of Brassica juncea and Brassica napus leaves. Plant Sci, 2006, 170: 511-519

[25] Gomes-Junior R A, Moldes C A, Delite F S, Pompeu G B, Gratao P L, Mazzafera P, Lea P J, Azevedo R A. Antioxidant metabolism of coffee cell suspension cultures in response to cadmium. Chemosphere, 2006, 65: 1330-1337

[26] Davies P J. The plant hormones: their nature, occurrence and function. In: Davies P J ed. Plant Hormones, Biosynthesis, Signal Transduction, Action! Dordrecht, The Netherlands: Kluwer Academic Publishers, 2004. pp 1-15

[27] Wilkinson S, Davies W J. ABA-based chemical signaling: the co-ordination of responses to stress in plants. Plant Cell Environ, 2002, 25: 195-210

[28] Yakimova E T, Kapchina-Toteva V M, Laarhoven L J, Harren F $\mathrm{M}$, Woltering $\mathrm{E} \mathrm{J}$. Involvement of ethylene and lipid signalling in cadmium-induced programmed cell death in tomato suspension cells. Plant Physiol Biochem, 2006, 44: 581-589

[29] Overmyer K, Tuominen H, Kettunen R, Betz C, Langebartels C, Sandermann H, Kangasjarvi J. Ozone-sensitive Arabidopsis $r c d l$ mutant reveals opposite roles for ethylene and jasmonate signaling pathways in regulating superoxide-dependent cell death. Plant Cell, 2000, 12: 1849-1862

[30] Tambussi E A, Bartoli C G, Beltrano J, Guiamet J J, Araus J L. Oxidative damage to thylakoid proteins in water stressed leaves of wheat (Triticum aestivum). Physiol Plant, 2000, 108: 398-404

[31] Liu J G, Zhu Q S, Zhang Z J, Xu J K, Yang J C, Wong M H. Variations in cadmium accumulation among rice cultivars and types and selection of cultivars for reducing cadmium in the diet. J Sci Food Agric, 2005, 85: 147-153 